\title{
Apresentação do dossiê “A Organização Internacional do Trabalho e as Américas: conexões e influências"
}

Laura Caruso*

Universidad Nacional de San Martín (UNSM), San Martín, Buenos Aires, Argentina

Norberto O. Ferreras ${ }^{*}$

Universidade Federal Fluminense (UFF), Niterói, RJ, Brasil

Em 2019, foi comemorado o centenário da Organização Internacional do Trabalho, a mais antiga organização internacional em atividade. A OIT foi criada como uma dependência da Liga das Nações, que sobreviveu à reformulação do sistema internacional - posterior à Segunda Guerra Mundial e à Guerra Fria -, que incluiu as disputas pela hegemonia das organizaçóes internacionais. Em diferentes locais, por ocasião do centenário, foram realizadas celebrações como o lançamento de livros, atividades artísticas, encontros de especialistas em Direito do Trabalho e de Historiadores interessados no legado desse centenário. A própria OIT realizou atividades comemorativas de diferentes tipos. O centenário foi um momento de comemoração, autocongratulação e de reflexão pelo caminho andado em todo esse tempo. A OIT passou por diferentes etapas e transformações, incorporando novos temas, interesses e reformulando certas abordagens. Algumas coisas mudaram significativamente - a América Latina já teve um Diretor Geral - e algumas temáticas foram incorporadas - abandonando o tom paternalista existente nos primeiros anos e outros temas, como as trabalhadoras domésticas - que passaram a fazer parte do grupo de profissóes contempladas e protegidas. Outras permanecem inalteradas desde o início, como a necessidade de ratificação nacional das decisóes tomadas em Genebra e a presença de trabalhadores e empresários no processo de tomada de decisóes.

Ao longo desses cem anos, a OIT cresceu, incorporando países que nem sequer existiam no momento da sua criação. Hoje em dia, ao todo, são 187 os países membros, um número um pouco menor do que os 193 que integram a Organização das Naçôes Unidas, que são superados pelos

\footnotetext{
*Dra. Laura Caruso. E-mail: lauracaruso@gmail.com. https://orcid.org/0000-0001-6556-5705.

** Dr. Norberto O. Ferreras. E-mail: ferreras@vm.uff.br. https://orcid.org/0000-0003-3801-0418.
} 
211 que integram a Federação Internacional de Futebol Associado. Esta quantidade de filiados e os seus cento e um anos de trajetória podem nos levar a pensar num caminho de êxitos constantes, porém, a OIT atravessou uma série de dificuldades nos primeiros anos, bem como durante e depois da Segunda Guerra Mundial. As fortes disputas ideológicas do período Entreguerras e ao longo da Guerra Fria fizeram com que a sua existência fosse, às vezes, subestimada ou fosse transformada em palanque para confrontos entre os adversários ideológicos. É importante destacar que a Liga das Nações, entidade-mãe da OIT, não sobreviveu aos conflitos ideológicos que levaram à Segunda Guerra Mundial e que a ONU, surgida ainda durante a Segunda Guerra Mundial, teve enormes dificuldades até ser aceita como um centro de discussão e debate das relações entre os diversos países.

Tendemos a naturalizar a existência desta instituição e de outras que fazem parte dos organismos internacionais. Porém, quando estudamos os diversos momentos pelos quais atravessou a OIT, assim como a diversidade de questóes de que tratou e a necessidade de estabelecer um equilíbrio entre formações econômicas e sociais muito diferentes, então, compreendemos que a sua existência tem a ver com a perícia das suas primeiras conduçóes e o compromisso dos representantes para que a principal questão social do século XX, o Trabalho, tivesse um espaço de importância nas relações entre os países. O esforço coletivo teve como ponto de partida a demanda dos trabalhadores no final da Primeira Guerra Mundial e, a poucos anos da revolução triunfante na Rússia, para que as suas problemáticas fossem contempladas e legitimadas como importantes no convívio social e na reconfiguração das sociedades europeias no imediato Pós-Guerra. Neste primeiro momento, a existência da OIT não contribuiu para a incorporação plena dos trabalhadores na vida social e, ainda, normalizou o trabalho colonial. Digamos que o objetivo principal da OIT era o combate à ameaça comunista, esvaziando as reclamaçôes operárias. Mesmo assim, esta instituição deve ser valorizada por ter colocado em pauta e estimulado o debate sobre as questóes fundamentais do trabalho desde as oito horas de trabalho diárias ao trabalho forçado, o trabalho infantil e feminino, o trabalho marítimo, entre tantos outros.

Nos anos posteriores à Segunda Guerra Mundial, a OIT foi assumindo uma posição cada vez mais técnica, discutindo como as tarefas devem ser desempenhadas, a carga e as condições do trabalho em cada um dos âmbitos em que as tarefas são desenvolvidas e a forma em que as tarefas devem ser desenvolvidas. Ao mesmo tempo em que estabelecia parâmetros técnicos, também politizava o seu acionar reformulando categorias, incorporando novos contingentes de trabalhadores e reconhecendo a importância do trabalho nas sociedades fora da produção capitalista. Esse reconhecimento permitiu que indígenas e comunidades tradicionais pudessem reivindicar direitos e um outro tipo de relação com os Estados Nacionais. De forma definitiva, esse reconhecimento deu elementos legais para a posterior existência de Estados Plurinacionais. A OIT também foi plataforma para denúncias de violações aos Direitos Humanos, pelo que o perfil técnico também foi acompanhado pela politização das suas ações.

Em síntese, a OIT é uma instituição que nos proporciona múltiplas possibilidades analíticas e representa um campo de estudos fértil e promissor. Veremos alguns exemplos nas temáticas desenvolvidas neste dossiê. É preciso mencionar que até dez anos atrás, os estudos sobre a OIT eram escassos, muitas vezes realizados por funcionários ou ex-funcionários da própria OIT. A partir do lançamento do Projeto Centenário, lançado pela OIT, foi que os estudos começaram a deslanchar. $\mathrm{Na}$ América Latina, o interesse pela OIT é crescente, porém, ainda engatinha, sendo um grupo importante mais limitado de historiadores. No Brasil, por exemplo, são pouquíssimos os pesquisadores do tema, mas há uma certa expectativa de crescimento e interesse sobre esse tema. Entendemos que este dossiê estimulará algumas novas pesquisas e interesses e revelará a existência de fontes e repositórios que podem renovar os estudos sobre a História do Trabalho no Brasil. 
No caso da Argentina, existe, desde 2015, a Rede Interdisciplinar OIT - América Latina, que reúne, num esforço coletivo, regional e interdisciplinar, investigadores e investigadoras de universidades de diversos países como Chile, Brasil, Argentina e Bolívia, entre outros, e que, desde então, na sua perspectiva latino-americana em relação à OIT e ao mundo do trabalho, publicou dois livros, um outro dossiê, organizou oficinas na Argentina (La Plata, 2015) e no Brasil (Niterói, 2017) reunindo muitos painéis, mesas-redondas e apresentaçóes ao longo dos seus cinco anos de existência. Este mesmo dossiê faz parte de uma trajetória comum, que esperamos que continue em franca expansão em relação aos temas, colegas e às produções.

Os artigos que compóem o presente volume da Revista Anos 90 reúnem um grupo de historiadores da América Latina. Em todos os casos, identificamos um diálogo entre a História nacional do Trabalho e a História dos Organismos Internacionais. O diálogo se dá de formas diferentes e identificam questóes próprias do vínculo estabelecido entre as partes. Três dos artigos situam-se no período Entreguerras, outro trata do imediato Pós-Guerra e o último deles aborda as décadas de 1950 e 1960. Ao mesmo tempo, a relação Genebra-América Latina é central em todos os casos. Seja abordando questões técnicas ou políticas, o vínculo entre a sede e os governos nacionais são de central importância para todos os autores. Dois artigos colocaram a ênfase em questóes técnicas como a maternidade e a produtividade, e o restante analisou as relações políticas entre as partes. Os países analisados são Argentina, Chile e México. O Chile é um dos países com um vínculo mais intenso e prolongado, com uma importante quantidade de Convençóes aprovadas, que, ainda, proporcionou importantes quadros técnicos, entre eles, o único Diretor Geral latino-americano, Juan Somavía, que exerceu essa função entre 1999 e 2012.

O primeiro artigo do dossiê é de autoria de Fabian Herrera León, que, em La Oficina Internacional del Trabajo en México: la visita de Edward J. Phelan y Stephen Lawford Childs en mayo de 1933, analisa o interesse da OIT em estabelecer um vínculo duradouro com o México. Esse país estava em processo de ingresso na OIT e na Liga das Nações. As visitas de Phelan e Childs, funcionários de alto escalão na OIT, tinham como objetivo discutir elementos técnicos e principalmente compreender a realidade mexicana pós-revolucionária. O México estava excluído do convívio internacional desde a Revolução e pretendia a sua incorporação nas organizaçóes internacionais, assim como pretendia discutir a sua compreensão das relações entre os países e discutir a forma como se organizava o trabalho e a sociedade nesse país. A visita dos representantes permitia discutir certos elementos da organização da OIT, como a representação corporativa, e resolver a representação operária nas Conferências Internacionais do Trabalho, ante a disputa entre as confederações mexicanas e o vínculo que tinham com o Estado.

O artigo de Paula Lucia Aguilar, Entre la protección y la igualdad: la OIT y el seguro por maternidad en perspectiva regional 1936-1939, analisou os debates acontecidos nas Conferências Pan-Americanas do Trabalho que tiveram lugar na década de 1930. As Conferências foram organizadas pela OIT e os países do continente americano. O interesse da autora está centrado no estatuto da mulher trabalhadora frente à maternidade e às dificuldades para manter o seu salário. A maternidade entrava no debate regional como uma questão vital no processo de expansão da classe trabalhadora no momento de rápida expansão da industrialização e do crescimento da presença feminina no mercado de trabalho.

Andrés Stagnaro analisa a relação da OIT com outro país latino-americano que tem um forte movimento operário, a Argentina. No artigo De la incertidumbre a la estabilización: el devenir de los muchachos peronistas en Ginebra. La representación obrera Argentina ante la OIT (1945-1955), é apresentada uma experiência inovadora do governo peronista, os agregados operários nas embaixadas. 
Stagnaro apresenta a forma como a Argentina lutava contra o isolamento no imediato Pós-Guerra com uma diplomacia que privilegiava as questões sociais e, portanto, via na OIT um espaço para recompor os seus vínculos internacionais, não sem tensões. A Argentina, governada pelo General Juan Domingo Perón, tinha uma política trabalhista que dialogava com a OIT, porém, precisava resolver as tensões existentes em relação à escolha da representação operária, principalmente com o vínculo estreito existente entre o Estado e a principal central operária, a Confederação Geral do Trabalho.

No caso estudado por Silvia Simonassi em El problema de la productividad en Argentina: perspectivas locales y transnacionales entre el primer peronismo y el frondicismo, temos uma análise de uma política discutida fortemente em Genebra que impactou fortemente na Argentina. A questão da produtividade e a capacidade produtiva da indústria argentina e, no caso dos seus trabalhadores, foi iniciada durante o governo de Juan Domingo Perón e se estendeu pelos vinte anos seguintes. Embora o governo de Perón tenha colocado a produtividade em discussão, nos governos posteriores, durante a proscrição do peronismo, a produtividade foi utilizada pelo governo ditatorial posterior ao golpe que depôs Perón e, no governo de Arturo Frondizi, como um avanço empresarial e estatal, para controlar o processo produtivo. Os trabalhadores, por sua vez, identificaram neste debate técnico uma forma de disputa com os governos antiperonistas.

O último estudo apresentado neste dossiê corresponde à autoria de Patricio Herrera e Juan Carlos Yáñez, Saberes compartidos entre América Latina y la Organización Internacional del Trabajo: un recuento historiográfico contemporâneo. O artigo é uma importante contribuição para compreender a construção de um campo de estudos devido ao mapeamento realizado sobre os estudos em relação à OIT. O seu foco prioritário é o Cone Sul, em grande medida, devido a que esse espaço é o que concentra a maior quantidade de estudos. Os autores mostram que os estudos têm se concentrado no período Entreguerras e no imediato Pós-Guerra. É um artigo importante pela sua capacidade de síntese de um determinado momento da produção regional sobre a OIT, bem como as relações e influências desta organização na região.

Em síntese, o dossiê mostra que este é um campo fértil de estudos e que está em crescimento e expansão. A OIT segue sendo uma instância-chave na legitimação e formação de consensos em relação à concepção e às definições do que é trabalho, quem são consideradxs sujeitos desse mundo e suas diversas formas, como deveriam ser reguladas, quais são os seus direitos básicos associados aos homens e às mulheres que o exercem. No atual contexto, as próprias formas do trabalho e com elas o labor $\mathrm{da}$ OIT viram-se profundamente afetados pela pandemia mundial, as diversas formas que adotou a quarentena em cada contexto nacional e regional, e as prementes situaçóes de desconhecimento de Direitos, desregulação trabalhista laboral e demais situaçóes limites em campos, tais como o chamado trabalho de plataformas, os novos sujeitos ficaram visíveis nesta conjuntura como os repartidores de aplicações, afirmação que corresponde à nossa região e que visibilizou e demandou a intervenção e o debate sobre essas questóes, com particular intensidade na Argentina e aqui no Brasil. Em particular, o Brasil ainda precisa voltar o seu olhar para as relaçóes internacionais e com os organismos internacionais. Compreender a importância e influência mútua entre as partes e a necessidade desses organismos políticos e técnicos no estabelecimento ou na legitimação de políticas. Esperamos que o dossiê ajude a alavancar novos estudos e debates sobre o tema. 